\title{
PROCESSO DE AGLOMERAÇÃO MECÂNICA DE PÓS E LAMAS*
}

Eduardo de Oliveira Cabral
César Fernando Andina Eijo
Elen Mancini Santi Pauletto $^{2}$

\section{Resumo}

O trabalho apresenta uma comparação entre os principais tipos de processo de aglomeração mecânica de pós e lamas, com foco nas tecnologias de tambor e prato rotativo, misturador horizontal e misturador intensivo vertical, destacando as vantagens e desvantagens de cada processo de acordo com o objetivo final.

Palavras-chave: granulação, aglomeração mecânica, mistura

\section{MECHANICAL AGGLOMERATION PROCESS OF POWDERS AND SLUDGES}

\section{Abstract}

This paper presents a comparison between some types of mechanical agglomeration process of powders and sludge, focusing on rotating drum, disk pelletizer, horizontal and vertical intensive mixer, highlighting the advantages and disadvantages of each process according to the final objective.

Keywords: granulating, mechanical agglomeration, mixing.

1 Engenharia de Materiais, Pós-graduado em Administração, Vendas e Recursos Humanos, Gerente de Vendas, Eirich Industrial Ltda., Jandira, SP, Brasil

2 Lic. em Comercialização e Administração de Empresas, MBA Negócios, Vendas, Eirich Industrial Ltda., Jandira, SP, Brasil

3 Comunicação Social: Publicidade e Propaganda, Publicitária, Analista de Marketing, Eirich Industrial Ltda., Jandira, SP, Brasil 


\section{INTRODUÇÃO}

\subsection{Aglomeração e granulação}

Apesar de terem definições diferentes pelo dicionário da língua portuguesa, aglomeração (juntar, reunir, acumular, amontoar) e granulação (o ato de granular), industrialmente tem sentidos semelhantes: entende-se como granulação o conjunto de grânulos com formas e granulometrias mais definidas e, a aglomeração, como o conjunto desses grânulos, porém sem forma e distribuição bem definidas.

Neste trabalho, adotaremos o uso das palavras granulação e granulado, porém pode se entender também como aglomeração e aglomerados.

\section{2 . O processo}

A granulação mecânica é um processo onde material em pó e/ou sólido aderem entre si ao serem movimentados circularmente com ajuda ou não de uma substância ligante, resultando em um aumento de tamanho das partículas, chamados granulados.

Figura 1: Processo de granulação mecânica

Adição de Líquidos
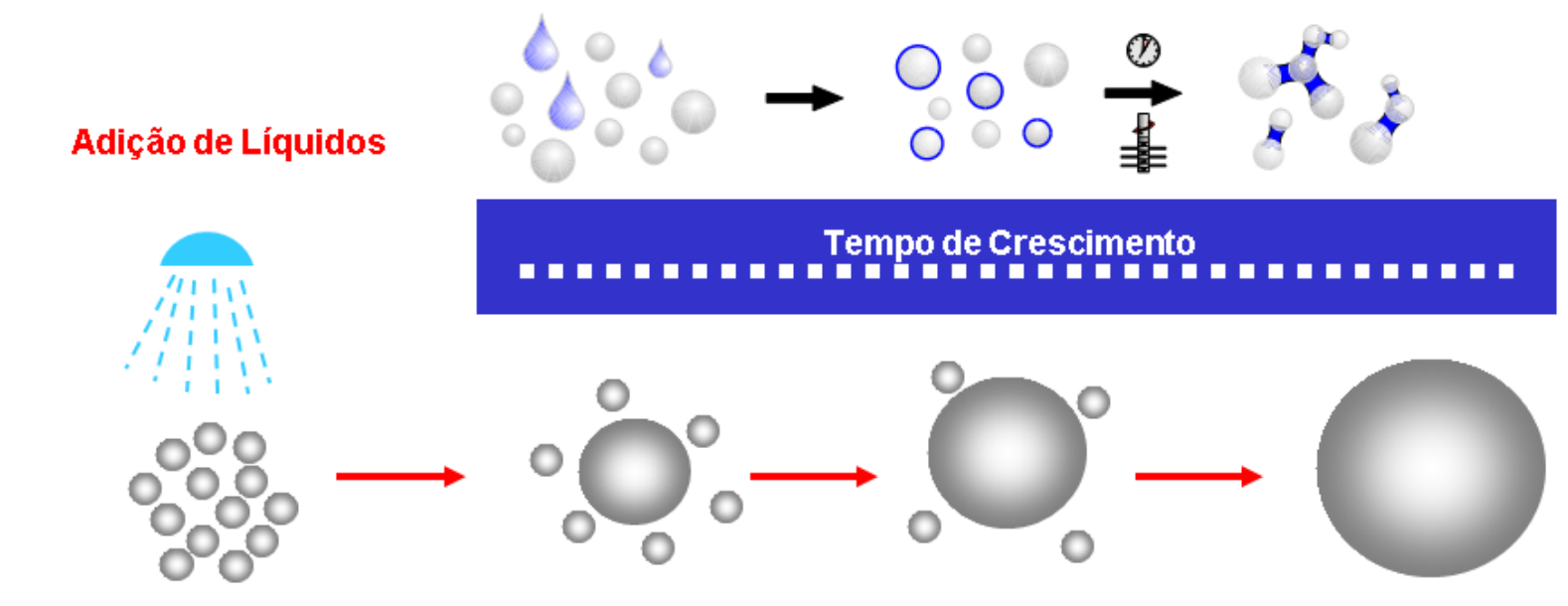

Tempo de Crescimento 
Figura 2: Resultado visual do granulado após granulação mecânica.

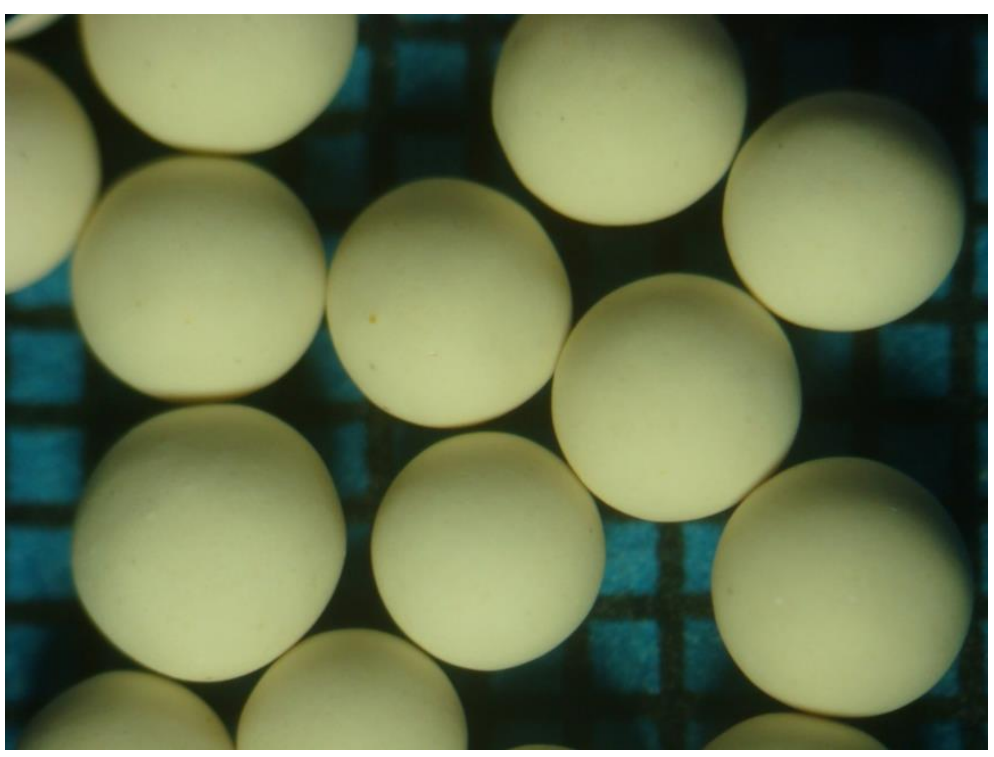

Caso a distribuição granulométrica dos pós seja muito larga, o efeito abaixo pode ser notado:

Figura 3: Processo de granulação mecânica com faixa de distribuição granulométrica larga.

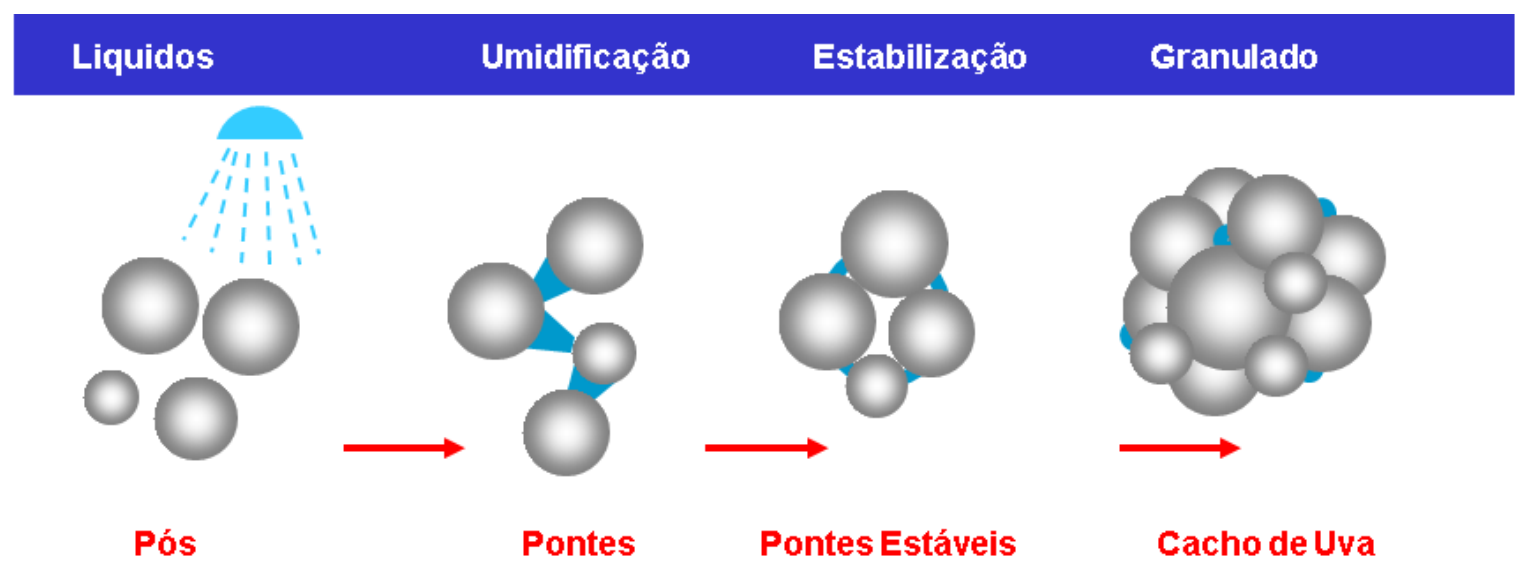


Figura 4: Aspecto visual do granulado após granulação mecânica com faixa de distribuição granulométrica larga.

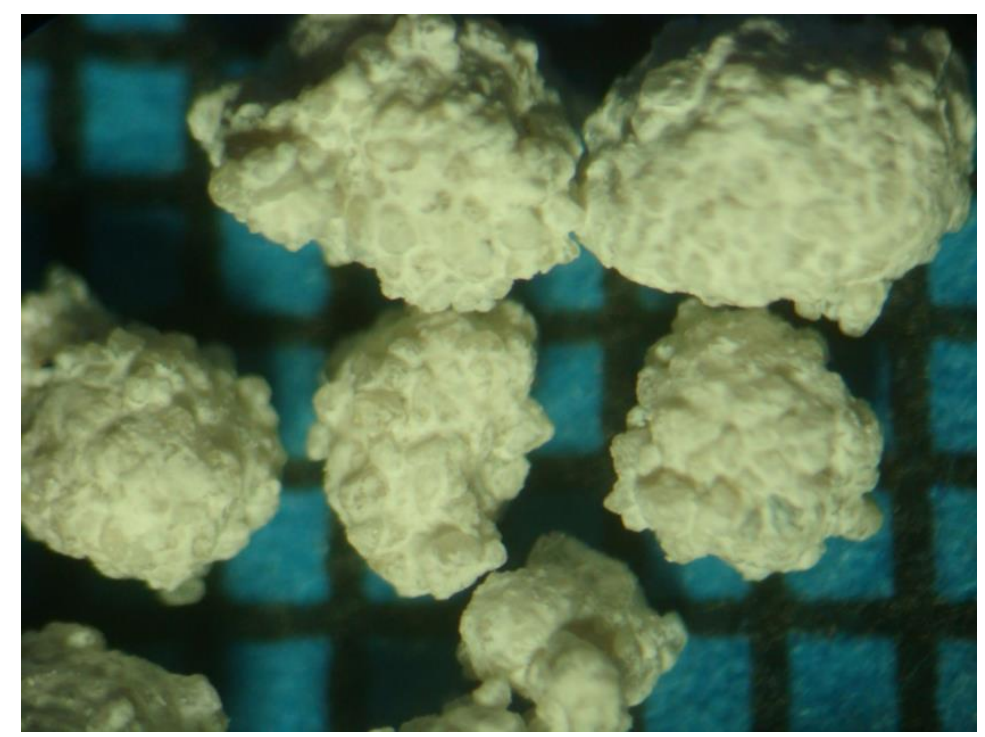

Outra situação é quando temos pós finos, que podem gerar um granulado com superfície regular, porém, com alguns poucos materiais grossos em sua composição.

Figura 5: Processo de granulação mecânica de pós finos e materiais mais grossos na composição.

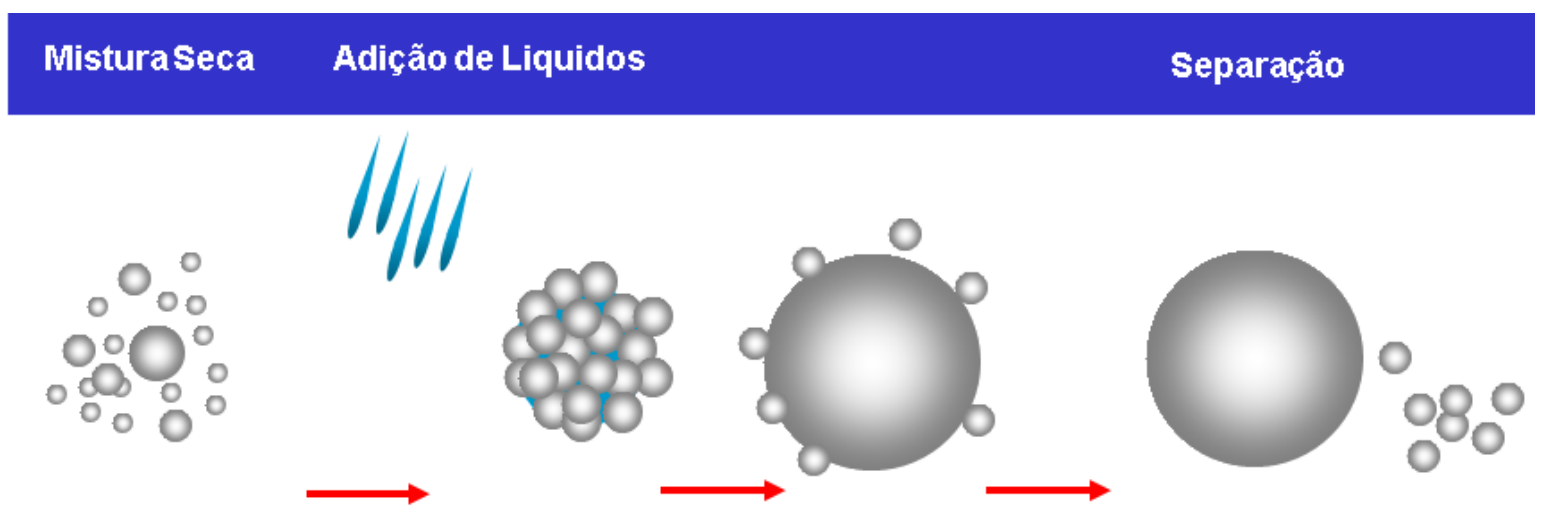

Cacho de Uva 
Figura 6: Aspecto visual do granulado composto de pós finos e materiais mais grossos.

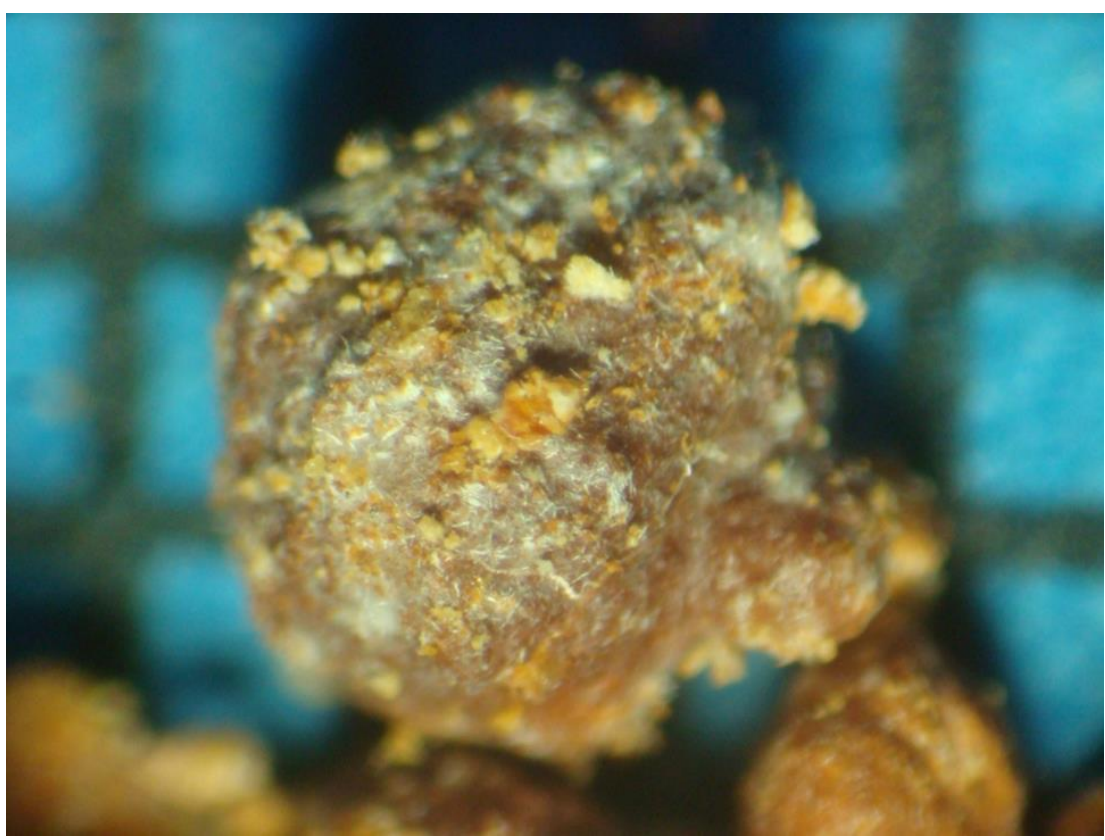

\subsection{Utilidade e vantagens}

Os granulados são comumente utilizados em diversas indústrias, dentre elas a siderúrgica e na obtenção de resíduos industriais. Por meio da granulação mecânica, os granulados se encontram em uma faixa granulométrica de 0,1 até $25 \mathrm{~mm}$ e podem ser tanto o produto final quanto o intermediário.

Algumas das vantagens e razões pelas quais se justificam a utilização de materiais granulados:

\subsubsection{Aumentar a fluidez de um material}

Em muitos processos é necessário que os materiais tenham fluidez suficiente para serem movimentados com maior facilidade. Em sua grande maioria, os pós finos possuem péssima fluidez, porém, após granulados conseguem boa capacidade de escoamento. 
Figura 7: Comparativo de escoabilidade entre um material granulado e composto de pós finos.

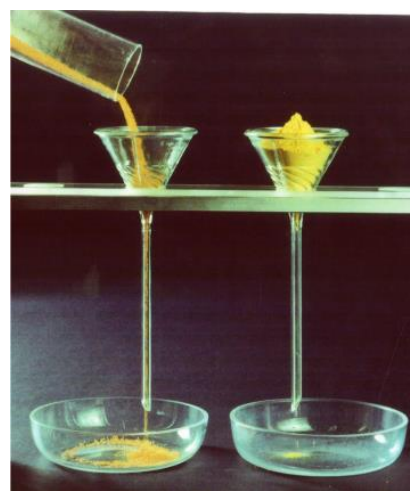

\subsubsection{Evitar a segregação de formulações}

Ao serem transportadas, misturas de pós possuem tendência de segregar por diferença de densidade e/ou tamanho de suas partículas. Ao granular a formulação evita-se esta segregação indesejada da mistura durante o transporte.

\subsubsection{Compactação}

O material aglomerado é mais compacto, o que apresenta uma série de vantagens como evitar a captação pelo sistema de despoeiramento na entrada dos fornos e nos transportadores, diminui o volume do material por unidade de massa, reduzindo assim o custo de estocagem e transporte.

Figura 8: Representação do material antes de depois de compactado.
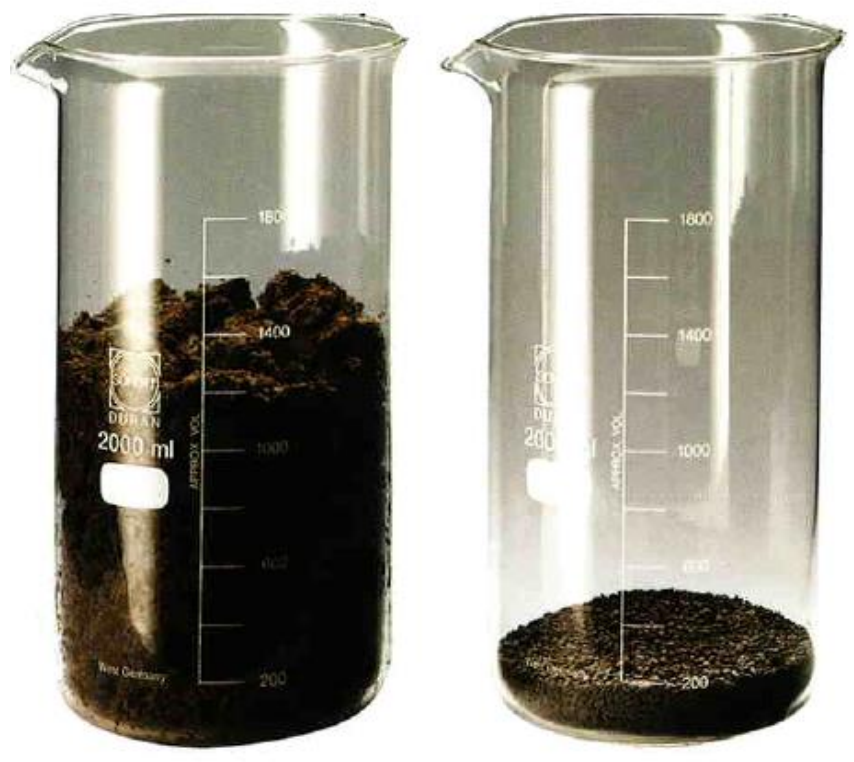


\subsubsection{Eliminação de pós}

Por terem um peso maior que o material em pó, os granulados tem a vantagem de não se dispersarem facilmente no ambiente. Alguns pós também, por suas características intrínsecas, ao serem respirados podem levar a doenças pulmonares, como por exemplo, a silicose.

\subsubsection{Aumenta permeabilidade de fornos}

Os granulados, por terem características arredondadas, geram maior espaço entre elas, o que permite melhor fluxo de gases quentes entre os materiais, promovendo melhor controle e consumo energético em fornos, como por exemplo, nos fornos de sínter e pelotas.

\subsubsection{Maior valor agregado}

Nos casos onde se pode vender o mesmo produto em pó ou na forma granulada, geralmente o produto granulado tem maior valor agregado, devido ao melhor manuseio. Esse é caso de fertilizantes, onde as máquinas automáticas necessitam do produto granulado para maior eficiência de adubação.

\subsection{Tipos de processos}

Agora que já falamos sobre as vantagens da granulação de materiais, vamos citar os principais tipos de processos.

\subsubsection{Tambor rotativo}

O tambor rotativo basicamente é um cilindro que gira sobre o seu próprio eixo, podendo ou não ter aletas de movimentação dentro de seu corpo. Possui uma pequena inclinação, que facilita o transporte do material em seu interior.

O tambor promove um rolamento das partículas, que por força de adesão, faz com que as partículas se aglomerem. O diâmetro e comprimento do equipamento são os parâmetros de projeto enquanto velocidade de rotação, umidade e granulometria de entrada são os parâmetros de processo.

Como podemos verificar na imagem abaixo, o ideal é ter a rotação tal que se produza um fluxo similar a um "rim". No caso desse equipamento, não se aconselha a utilização de velocidades altas, a ponto de gerar forças centrípetas ou quedas no produto, ou velocidades muito baixas, afim de não produzir o rolamento das partículas. 
Figura 9: Representação gráfica do fluxo de material em um tambor rotativo.
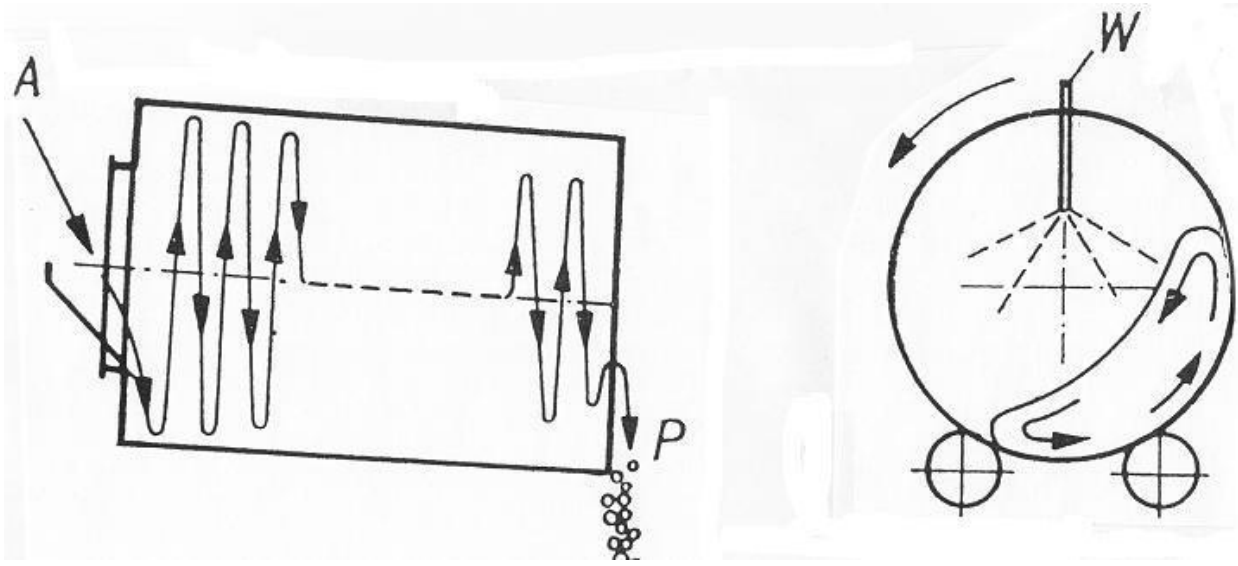

Em muitos casos, para se produzir uma curva granulométrica mais fechada, se utiliza o equipamento com uma grande carga circulante, como por exemplo, $200 \%$ de sua capacidade.

\subsubsection{Prato rotativo}

O prato rotativo basicamente é uma panela rotativa, que possui raspadores internos que limpam e melhoram o fluxo de material em seu interior. O prato promove um rolamento das partículas, que por força de adesão, faz com que as partículas se aglomerem. O diâmetro e altura da borda são os principais parâmetros de projeto enquanto velocidade de rotação, inclinação, umidade e granulometria de entrada são os parâmetros de processo.

Como podemos verificar na imagem abaixo, o próprio giro do equipamento já faz uma classificação do produto, em que os granulados mais grossos e com mais peso, vão se deslocando para cima e próximo da borda de saída. Controlando a inclinação e a velocidade do equipamento, é possível ter um bom controle granulométrico do material.

Figura 10: Representação gráfica do fluxo de material em um prato rotativo.

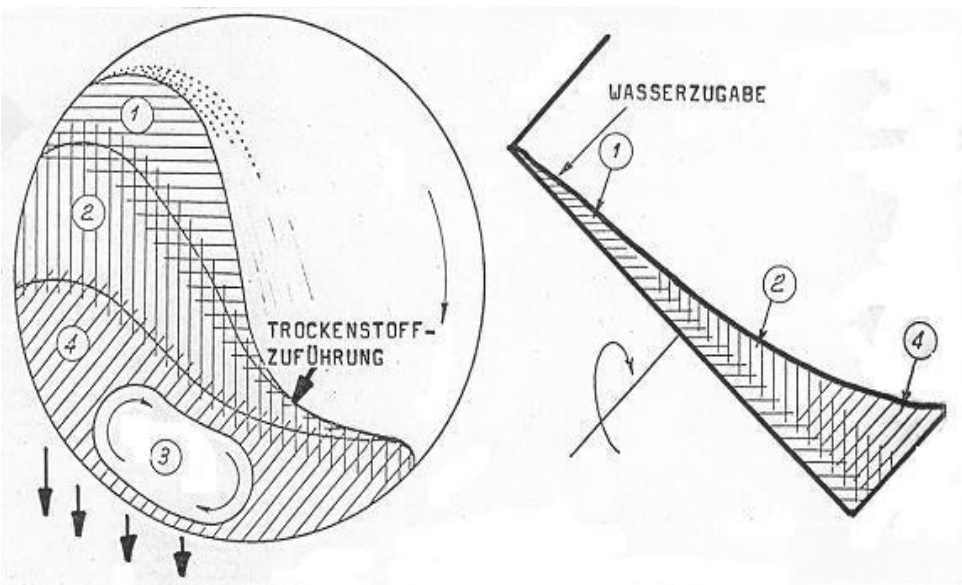




\subsubsection{Misturador horizontal}

No misturador horizontal a cuba cilíndrica é fixa, sendo que o promotor do movimento é um eixo longitudinal centralizado que inclui elementos de mistura que giram bem próximos da superfície interna da cuba. O material entra em contínuo por um extremo do cilindro e é forçado a seguir um percurso em forma de parafuso - gerando a aglomeração - até o extremo oposto, por onde é descarregado.

Os parâmetros do projeto são o diâmetro e longitude do cilindro, sendo a velocidade de rotação do eixo, o formato dos elementos de agitação, granulometria e umidade são os parâmetros do processo. Cabe consignar que a velocidade de rotação do eixo deve ser limitada para evitar que os agitadores gerem forças centrípetas que impulsem o material para as paredes internas do cilindro, fazendo com 0 que 0 equipamento perca sua funcionalidade.

Figura 11: Fluxo de material em um misturador horizontal.

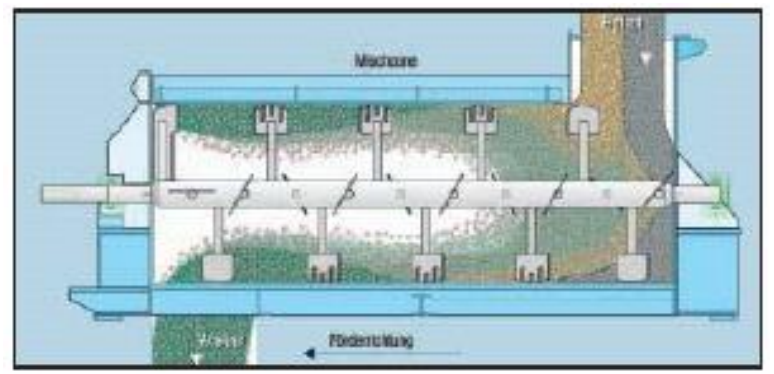

Em muitos casos existem ainda elementos intensificadores de alta rotação (choppers) inseridos nas laterais, a intervalos regulares ao longo do cilindro, que ajudam na dispersão e mistura do material, pelo que alguns também chamam de misturador horizontal intensivo a este tipo de equipamento.

\subsubsection{Misturador intensivo vertical}

O misturador intensivo vertical possui em seu conceito uma cuba rotativa, que promove a movimentação e rolamento das partículas em seu interior. Em combinação com a ferramenta estática (raspador de parede e fundo) faz com que o material se direcione para a ferramenta excêntrica de alta intensidade, assim agregando a energia necessária para o processo.

O material é granulado dentro do equipamento por:

- Rolamento dos materiais feitos pela cuba (semelhante ao prato e tambor rotativo)

- Energia empregada pela ferramenta de alta intensidade. Ao contrário do que se pode imaginar, na fase inicial de crescimento dos aglomerados é necessária uma energia entregue ao sistema para:

a. Misturar os ligantes e água com os pós (quando necessário) 
b. Acelerar a chegada da umidade a superfície do granulado por forças capilares

c. No final do ciclo, controlar o tamanho dos over-size.

O interessante deste equipamento é que seu modo de operar permite maior flexibilidade na entrega de energia ao material, pois a cuba leva o produto processado à ferramenta de alta intensidade e essa velocidade de rotação da ferramenta pode ser variada de forma controlada em um amplo range (desde velocidades muito baixas, como $1 \mathrm{~m} / \mathrm{s}$, até mais altas, como $40 \mathrm{~m} / \mathrm{s}$ ).

O volume e tipos de ferramentas são variáveis de projeto e velocidade de rotação da ferramenta de alta intensidade, tempo de residência, umidade e granulometria são as principais variáveis de processo.

Figura 12: Princípio de mistura do misturador intensivo vertical.

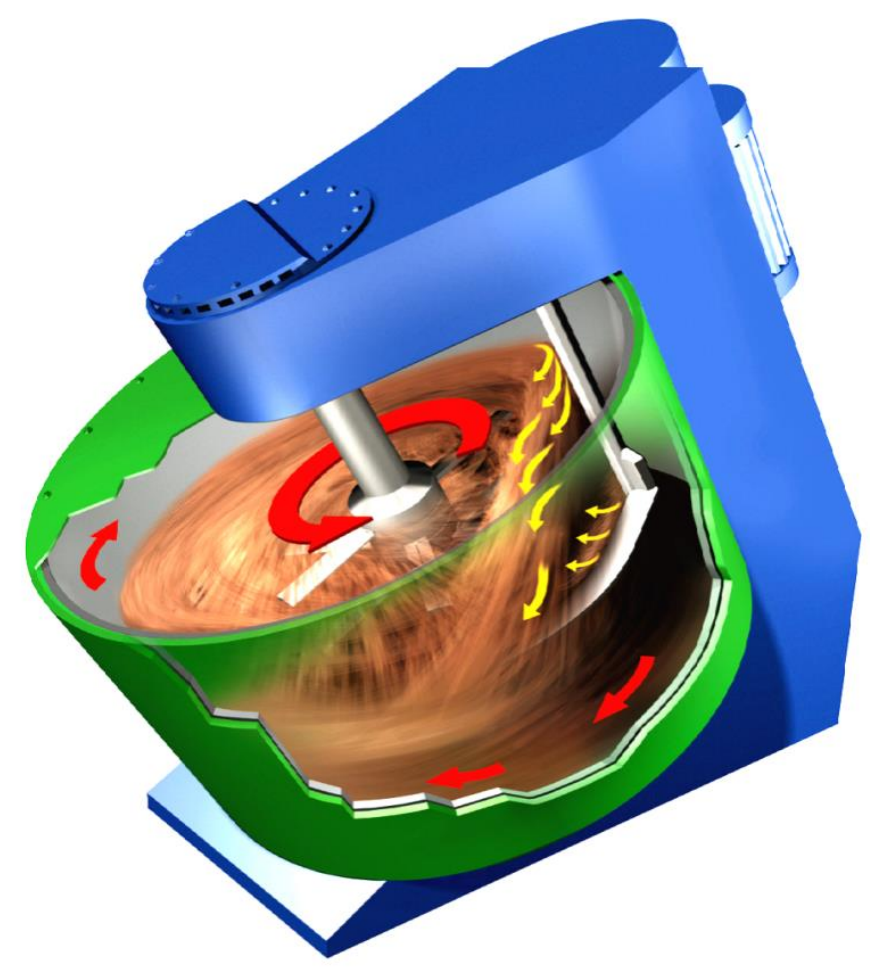

\subsection{Características}

\subsubsection{Distribuição Granulométrica}

A distribuição granulométrica, mais estreita ou mais aberta e/ou mais grossa ou mais fina, é definida basicamente pelo processo subsequente ao da granulação, quando o granulado é um produto intermediário, ou por sua aplicação, quando já se trata de um produto final.

Além da distribuição granulométrica do produto é importante destacar que a granulometria das matérias-primas é de suma importância para a obtenção dos granulados. Como tendência (ou seja, existem casos que a regra não vale), matérias-primas mais finas, por terem maior área superficial, 
apresentam melhor granulação e maior interação entre as partículas, facilitando a estabilidade dos granulados formados.

\subsubsection{Umidade}

Com relação à umidade, o importante nesse conceito é a umidade livre, que é a qual será utilizada para formação das pontes, as quais irão proporcionar a aglomeração.

Essa umidade livre, como diversos estudos mostram, deve estar em um máximo de 90 a $95 \%$ do volume dos poros do material granulado. Acima desses valores, a tendência é a formação de lamas.

Outro ponto crucial quando falamos de umidade é o índice de "molhabilidade" das matérias-primas. Para conseguir controlar o processo de granulação, a umidade deve estar em toda a superfície do granulado, ou seja, deve ter um índice de "molhabilidade" alto. Nos casos em que esse índice é baixo, aditivos para quebrar as tensões superficiais devem ser usados.

Conforme pode ser visto nas figuras abaixo, para se conseguir um granulado, a umidade deve estar entre os pontos "b" e "c", onde nem todos os poros entre as partículas foram preenchidos pela umidade.

Figura 13: Umidade no granulado.

a)

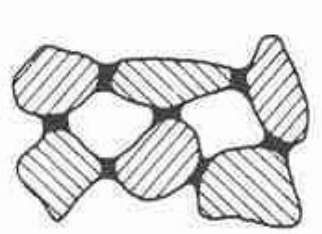

b)

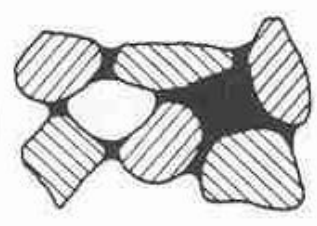

c)

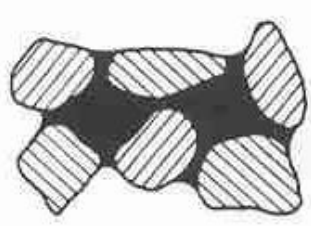

d)

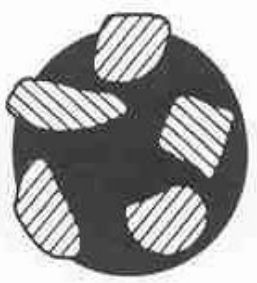

Figura 14: Gráfico de forças de mistura e líquidos.

essencialmente determinado por pk

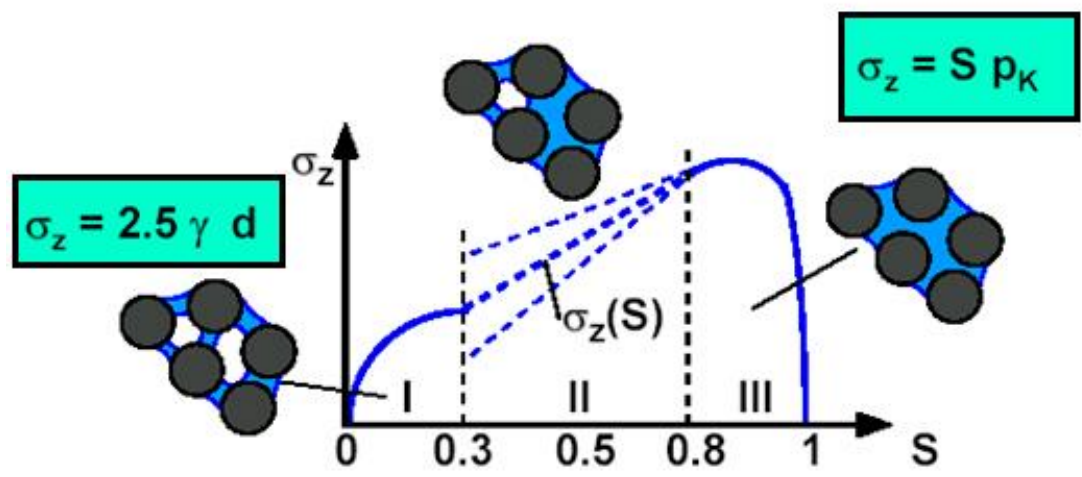

- pk é descrito pela curva de pressão capilar 


\subsubsection{Estabilidade}

A estabilidade é uma característica do granulado depois de preparado, em muitos casos, após seco. É quanto o granulado consegue resistir, ainda na forma de granulado, após os processos subsequentes.

Pontos que podem ser determinantes para a estabilidade do granulado:

- Tecnologia utilizada na preparação.

Faremos mais adiante, na conclusão, um comparativo entre as tecnologias abordadas neste trabalho.

- Tipo de secador a ser utilizado.

O tipo de secador é importante considerando dois aspectos: o primeiro com relação a quanto de abrasão o secador gera ao produto. Por exemplo, secadores rotativos geram maior cisalhamento que secadores de leito fluidizado. Outro ponto importante é quão brusca é a variação de temperatura, tanto no aquecimento quanto no resfriamento. Como por exemplo, choques térmicos podem gerar micro fraturas que diminuem a resistência e estabilidade do granulado.

- Tipo de ligante ou reações químicas que foram utilizadas.

Quando a interação entre as partículas não é suficiente, geralmente se utiliza ligantes que irão melhorar essa interação, tanto por efeitos físicos como reações químicas.

- Distribuição granulométrica das matérias-primas.

Conforme já comentado acima, distribuições mais abertas e materiais mais finos tem uma melhor tendência de aglomeração que o oposto.

\subsubsection{Textura}

Textura significa o quão acabada está a superfície do granulado. A importância da textura está nos casos onde se quer maior fluidez possível, sendo necessária uma superfície lisa ou em casos estéticos, como uma melhor aparência do produto final, como por exemplo, no caso de argilas expandidas usadas em decoração de vasos e plantas.

A granulometria das matérias-primas está diretamente ligada a esse efeito, e matérias-primas mais finas têm a tendência de melhorar a superfície do produto.

\section{RESULTADOS E DISCUSSÃO}

Tendo como base os conceitos discutidos previamente, apresentamos abaixo as diferenças entre as tecnologias, focando nos aspectos de segregação, compactação, distribuição granulométrica e estabilidade dos granulados. 


\subsection{Segregação}

A grande diferença entre os equipamentos considerados é que, prato e tambor rotativos, diferentemente dos misturadores horizontais e verticais, não são misturadores e não conseguem fazer eficazmente uma homogeneização dos materiais.

Por efeito da gravidade, tanto o tambor como prato rotativo tendem a "desmisturar" os materiais, não resultando num granulado de formulação uniforme.

Especialmente para os casos que se faz necessária a utilização de algum aditivo, a mistura é de suma importância. Sem aditivos bem distribuídos no sistema, faz-se necessário aumentar sua quantidade, o que eleva os custos de produção. Nesses casos o indicado é a utilização de misturadores no sistema.

\subsection{Compactação}

Pratos e tambores rotativos não possuem a força de compactação necessária para a produção de granulados, por trabalharem apenas por rolamento.

Já o misturador horizontal possui maior força de compactação se comparado ao prato e tambor, porém numa faixa mais estreita, se comparado com o misturador intensivo. A velocidade periférica média de rotação do eixo, para o misturador horizontal, é de 6 a $9 \mathrm{~m} / \mathrm{s}$. Essa velocidade influencia em quanto de energia se pode adicionar a mistura e assim melhor compactar o granulado.

A grande vantagem do misturador intensivo vertical em relação às demais tecnologias é que sua força de compactação pode ser controlada numa faixa maior, - que permite melhor controle na compactação. Sua velocidade pode ser controladamente variada numa faixa que vai de 3 a $40 \mathrm{~m} / \mathrm{s}$.

\subsection{Distribuição Granulométrica}

Quanto à distribuição granulométrica, cada tecnologia possui uma característica bem específica.

O tambor rotativo possui um bom controle e pode produzir granulados com faixas entre 2 e $18 \mathrm{~mm}$. Quando se trabalha com carga circulante, a grande vantagem é que se consegue uma distribuição estreita de granulometria.

O prato pelotizado tem uma maior dificuldade de controle dos paramentros de processo e pode, como o tambor, conseguir granulometrias na faixa de 2 a $18 \mathrm{~mm}$. Como exemplo do mercado de fertilizantes, quando não se trabalha com uma mistura previa, o equipamento atinge em torno de $50 \%$ de granulados na faixa entre 2 e $4 \mathrm{~mm}$, o que pode ser incrementado para até $80 \%$ com a utilização de um misturador intensivo prévio ao prato.

Já a tecnologia de mistura horizontal apresenta um controle ruim da distribuição granulométrica. Quando a mistura parte de matéria-prima em pó com adição de água, este misturador não possui energia suficiente para realizar uma boa interação 
entre a água e os pós, dificultando assim a granulação. Sua faixa de distribuição granulométrica está normalmente entre 0,1 e $5 \mathrm{~mm}$.

A alternativa que apresenta melhor controle, por possuir uma energia variada, é o misturador intensivo vertical. $O$ controle energético nesse equipamento facilita a distribuição da água nos pós, melhorando a homogeneização e por consequência a faixa granulométrica. A faixa granulométrica obtida nesse equipamento varia de 0,1 a $5 \mathrm{~mm}$.

\subsection{Estabilidade}

Quanto à estabilidade, o tambor e o prato possuem as mesmas características: por não apresentarem compactação ideal, as partículas que formam os granulados ficam mais distantes, ocasionando maior porosidade e menor resistência. Como também não ocorre a mistura, os aditivos não são distribuídos uniformemente, fazendo com que os granulados apresentem pontos de fragilidade.

O misturador horizontal produz granulados com estabilidade intermediária entre os produzidos por tambor ou prato e os produzidos por misturador intensivo.

Os granulados com maior compactação dentre as opções são os produzidos por misturador intensivo vertical, que por serem efetivamente misturados, apresentam partículas mais próximas, melhor distribuição de aditivos, logo seu resultado é de baixa porosidade e maior resistência e por consequência, a melhor estabilidade dentre as tecnologias abordadas neste estudo.

\section{CONCLUSÃO}

A melhor tecnologia a ser escolhida depende do resultado que se deseja.

Se deseja alcançar granulometrias maiores que $6 \mathrm{~mm}$, com composições mais simples, sem uso de aditivo, as melhores tecnologias são o prato ou tambor rotativo, considerando os aspectos quanto a segregação, distribuição e resistência mencionados neste estudo.

Caso seja necessária mistura, aditivos e granulometrias menores que $6 \mathrm{~mm}$, as melhores opções são os misturadores horizontais e intensivos verticais, salvo os aspectos quanto ao baixo controle de faixa de granulometria com o uso do misturador horizontal.

Abaixo mostramos uma tabela comparativa que ilustra as diferenças entre as tecnologias de mistura intensiva e horizontal. 
Tabela 1. Comparativo Misturadores Intensivo vs. Horizontal

\begin{tabular}{|l|c|c|}
\hline \multicolumn{1}{|c|}{ Critério } & $\begin{array}{c}\text { Misturador } \\
\text { Intensivo }\end{array}$ & $\begin{array}{c}\text { Misturador } \\
\text { Horizontal }\end{array}$ \\
\hline Absorção de água (umidade) pelo pó & +++ & - \\
\hline Qualidade do granulado (aspecto óptico) & ++ & - \\
\hline Aumento controlado de partículas & +++ & + \\
\hline Dissolução de torrões & ++ & + \\
\hline Dissolução de grumos & ++ & ++ \\
\hline Autolimpeza permanente do misturador & +++ & -- \\
\hline $\begin{array}{l}\text { Combinação de misturador e ferramenta (s) para fluxo de } \\
\text { material }\end{array}$ & +++ & -+ \\
\hline
\end{tabular}

Fonte: Estudo Interno HKM.

\section{REFERÊNCIAS}

$1 \quad$ K.Sommer, Agglomeration/Instatisierung , Hochschulkurs 2002

2 W. Pietsch, Agglomeration Process, Wiley-VCH Verlag, Weinheim 2002 